\title{
AÇÕES DE CUIDADO DESEMPENHADAS PELO PAI NO PUERPÉRIO
}

\author{
Actions in care carried out by the father in the puerperism \\ Acciones del cuidados desempeñados por el papá \\ durante el puerperio
}

Eteniger Marcela Fernandes de Oliveira ${ }^{1}$

Rosineide Santana de Brito ${ }^{2}$

\begin{abstract}
RESUMO
Pesquisa exploratória-descritiva, qualitativa, desenvolvida com 15 pais, de janeiro a abril de 2006, em Natal/RN. Teve por objetivo analisar as ações desenvolvidas pelo homem durante o puerpério de sua companheira. A coleta efetuou-se por entrevista semiestruturada, sendo os dados tratados por meio da técnica de análise de conteúdo e analisados à luz dos princípios do Interacionismo Simbólico. Os resultados apresentam uma temática central - ações de cuidado em ambiente doméstico - e duas categorias: cuidando da companheira e da criança; e provendo o sustento da família. Conclui-se que os depoentes interagem e participam do puerpério oferecendo conselhos que remetem à prevenção, como o estímulo à deambulação; desenvolvem atitudes de dedicação e preocupação com a saúde do filho; consideram que a licença-paternidade não atende às suas necessidades; reconhecem que a companheira e o recém-nascido requerem mais dedicação e que desempenham papel de provedor no intuito de garantir o sustento familiar.
\end{abstract}

Palavras-chave: Cônjuges. Período Pós-Parto. Cuidado Pós-natal.

\begin{abstract}
This qualitative, exploratory-descriptive research was conducted with 15 fathers, in Natal, RN. The aim was to analyze the actions conducted by the father during the puerperal period of his spouse. Data were collected by semistructured interviews, treated by analysis of content and analyzed according to the principles of symbolic interactionism. The results indicate one central theme - care actions in the home environment - and two categories - caring for the spouse and the baby, providing financial support to the family. It is concluded that the men interact and participate in the puerperal period, while offering preventive advice, such as stimulating demabulation; demonstrate attitudes of dedication and worries with the child's health; consider that the paternal off work legal license does not attend their needs; and recognize that their spouse and the newborn requires more dedication and that they play a provider role while assuring the family's financial support.
\end{abstract}

Key-Words: Spouses. Post-Partum Period. Postnatal Care.

\section{Resumen}

Investigación exploratoria y descriptiva, cualitativa, desarrollada con 15 padres de familia, en Natal/RN. La pesquisa analizó las acciones desarrolladas por el papá durante el puerperio de su compañera. Los datos fueron recolectados por medio de la entrevista semiestructurada, organizados por la técnica de análisis de contenido y analizados bajo los principios del Interaccionismo Simbólico. Los resultados mostraron que existe un tema central - las acciones de atención yl cuidado en el ambiente doméstico - y dos categorías - cuidar de la pareja y del niño, sin dejar de lado el sustento de la familia. Se concluyó que estos padres conviven durante el puerperio ofreciendo consejos que remiten a la prevención, como estimular a la mujer a hacer caminadas; desarrollan actitudes de dedicación y preocupación con la salud del hijo; consideran que el permiso de trabajo por paternidad no contempla sus necesidades; reconocen que su familia requiere de mayor dedicación y que ejercen el papel de proveedores al garantir la protección financeira de la familia.

Palabras-clave: Esposos. Periodo de Posparto. Atención Posnatal

${ }^{1}$ Enfermeira, Mestre em Enfermagem pela UFRN. Brasil. E-mail: etenigerm@yahoo.com.br, ${ }^{2}$ Enfermeira, Doutora em Enfermagem pela USP/Ribeirão Preto, Professora Adjunta do Departamento de Enfermagem da UFRN. Brasil. E-mail: rosineide@ufrnet.com.br 


\section{INTRODUCÃO}

Com o advento do século XX, as mudanças socioeconômicas pelas quais passam a família brasileira estão, cada vez mais, favorecendo questionamentos acerca dos papéis sexuais. Podemos constatar uma maior solicitação feminina à participação masculina na esfera privada. As tarefas assumidas por mulheres, no mundo público, terminam por abrir espaços para a ajuda paterna, quer seja desempenhado atividades domésticas ou cooperando nos cuidados com os filhos ${ }^{1}$.

A ajuda paterna nos cuidados com a criança proporciona uma interação precoce e mais intensa entre pai-bebê, o que favorece o crescimento saudável da criança, além de transmitir segurança à mulher, pois a ajuda, indiretamente, a sentir-se mais amorosa e dedicada ao seu filho ${ }^{2}$. Assim, em paralelo ao lado racional e objetivo, podemos constatar o surgimento de um novo homem emocional e solícito na criação e educação dos filhos e nas tarefas domésticas'.

Tratando do ciclo gravídico-puerperal, muitos são os acontecimentos, sensações e sentimentos experimentados pelo homem. Entretanto, poucos são os trabalhos que apresentam considerações sob a perspectiva masculina durante essas fases da vida. Em meados da década de 90, alguns estudiosos reconhecem o direito e a necessidade da inclusão dos homens nos processos e relações advindas com a reprodução e a sexualidade. Levantam-se muitos questionamentos ligados à descoberta da sua vivência no exercício da paternidade, objetivando descobrir formas equitativas quanto à participação do pai perante as mulheres e ao seu tradicional papel de provedor?.

Assim sendo, na atual realidade em que nos encontramos, surge a necessidade de atender e acolher não somente a mulher - gestante, parturiente e/ou puérpera -, mas também seu marido/companheiro, garantindo a ambos a oportunidade de compartilhar sentimentos, vivências e, acima de tudo, auxiliandoos na construção de suas identidades maternas e paternas.

No entanto, aceitando o puerpério como um acontecimento que se desenvolve, muitas vezes, dentro de uma estruturafamiliar, ou seja, compreendendo mãe, pai e filho como seres interativos, não observamos citações que contemplem a presença do pai nesse processo. Além disso, considerando que a assistência de enfermagem atende a família em todos os seus ciclos de vida criança, adolescente, adulto e idoso -, ela precisa estar embasada em conhecimentos que promovam o bem-estar e a saúde de seus integrantes. Para isso, faz-se necessário conhecer aspectos imbricados dessa interação no pós-parto para só então oferecer solidamente e com segurança científica os cuidados de enfermagem.

A par dessas considerações pressupomos que, ao vivenciar o puerpério da companheira, o homem interage desenvolvendo ações de natureza diversas, as quais podem repercutir positiva ou negativamente no núcleo familiar. Sendo assim, questionamos: quais ações o homem desempenha ao vivenciar o puerpério de sua companheira? Diante do nosso questionamento, percorremos o seguinte objetivo: analisar as ações desempenhadas pelo homem durante o puerpério da companheira.

\section{REVISÃO DA LITERATURA}

Nas fases de gravidez e pós-parto, observamos como via de regra a participação do pai provedor na atenção às necessidades da sua companheira e família ${ }^{4}$.

Na verdade não se aceita mais a definição do pai típico, considerado aquele excepcionalmente provedor e desarticulado dos acontecimentos domésticos, já que vivemos em realidades multidimencionais. Em função disso, os papéis tanto do homem como da mulher têm sofrido transformações no que toca a sua função familiar: exige-se da mulher uma participação mais efetiva na manutenção e sustento da casa. Em contrapartida, 0 homem tem se voltado para as atividades domésticas e cuidados com os filhos.

Com base em estudos sobre as diferentes nuances da paternidade, concebemos que, em muitas partes do mundo, os pais estão assumindo um papel mais ativo no cuidado e criação de seus filhos. A participação do homem no processo da gravidez, em sentido mais amplo, é expressa por atitudes, comportamentos e sentimentos que se entrelaçam durante o ato de cuidar, concebido pelos maridos/companheiros como envolvimento afetivo para com a esposa e filho. Esse fato representa um alicerce à vivência do casal, contribuindo na consolidação da estrutura familiar ${ }^{5}$.

Acerca do parto, entende-se que a participação dos pais no nascimento traz o núcleo familiar para o ambiente institucional, constituindo um desafio e possibilidade de construção de uma assistência atenta à qualidade do nascimento das crianças. 0 homem deseja compartilhar o nascimento do filho para poder sentir a emoção de ser pai e permanecer com sua parceira. Entretanto, essa vontade nem sempre é concretizada devido às inúmeras desigualdades institucionais e de conduta profissional, tornando-se cada vez mais imprescindível advogar a presença desse homem como uma necessidade e prioridade para o bem-estar do casal e da família ${ }^{6}$.

Após o nascimento, o pai percebe as primeiras dez semanas da paternidade quase da mesma forma que a mãe. Esse período é caracterizado pela incerteza, pelo aumento das responsabilidades, pela interrupção do sono e pela incapacidade de controlar o tempo necessário para cuidar do bebể. Os homens também podem expressar preocupação quanto à diminuição da atenção da parceira. Além disso, a falta de reconhecimento da mulher quanto ao desejo do parceiro em participar da tomada de decisões, bem como a limitação do tempo disponível para ele estabelecer um relacionamento com o filho, tende a causar desequilibrio na relação conjugal. Porém, essa situação pode ser revertida à medida que ele vivencia essa experiência conjuntamente e desenvolve suas habilidades diante dos desafios de cuidar do seu descendente ${ }^{8}$. 
O cuidado direto do genitor com seu(s) filho(s) ainda ocorre de forma bastante limitada. Suas ações são muitas vezes mediadas por atitudes de outros integrantes da própria família, alijando-o de experiências valiosas referentes à paternagem. Além disso, a jornada de trabalho não permite a esse homem permanecer mais tempo em casa, pois grande parte da sociedade ainda entende que sua presença é, de certo modo, dispensável. Como exemplo, citamos a licença-paternidade: apesar de ser um ganho, ainda não responde às necessidades da participação paterna na família após o nascimento do filho. Desta forma, torna-se grande a diferença do envolvimento dos pais nos cuidados à criança ${ }^{4}$.

Sendo o puerpério um período ímpar do ciclo gravídicopuerperal, é durante esse intervalo que as idealizações surgidas na gestação são colocadas em prática, assim como vínculos e valores são construídos dentro de uma estrutura familiar. Logo, torna-se importante que os profissionais de saúde conheçam as emoções vividas pelo casal durante a gravidez, o parto e o puerpério, visualizando formas de estratégia de ajuda e consolidação dos papéis de pai e mãe ${ }^{8}$.

Esse período apresenta-se como um importante momento na vida reprodutiva dos casais. Após o nascimento, as expectativas criadas pelos pais durante a gestação são confrontadas com a realidade, ou seja, com a presença real da criança. As modificações ocasionadas nessa fase podem contribuir tanto para a aproximação como para o afastamento conjugal. Porém, um estudo constatou que o homem percebe mudanças no seu relacionamento durante a fase de aleitamento do filho, associando-as à criança, à companheira e à rotina doméstica. Em relação à companheira, os participantes referiram uma maior proximidade física e afetiva para com suas respectivas esposas. No entanto, concebem que elas afastamse física, emocional e sexualmente deles durante a fase de amamentação?.

Nesse ínterim, a prática da amamentação e a solicitação excessiva do recém-nascido consomem grande parte do tempo da puérpera. Esses fatos, quando mal entendidos, podem fazer com que o companheiro sinta-se privado de atenção e dos cuidados da companheira, chegando, de uma maneira mais grave, a considerar que sua mulher não se interessa mais por ele. Além disso, a atividade sexual do casal também tem forte possibilidade de ser afetada, já que a estimulação sexual e o orgasmo tendem a ser mais lentos e menos intensos. A mulher geralmente sente-se menos motivada para as relações sexuais durante as primeiras semanas após o nascimento ${ }^{10}$.

A rotina gerada pelos cuidados relativos à criança e à casa podem predispor a puérpera ao esgotamento físico, principalmente quando ela não procura ou não tem com quem conciliar as tarefas domésticas. Nesse momento, o companheiro pode tornar-se um grande aliado. Mostrar-se disponível, seja para ajudar ativamente a cuidar do bebê ou apenas ouvir a sua companheira, é atitude favorável à prevenção do desgaste psicológico da mulher, ao desenvolvimento do vínculo e ao exercício da paternidade?2.
Essas reflexões nos levam a considerar que o homem vivencia situações diversas durante o período gravídico-puerperal. As atitudes de apoio à companheira e de cuidado com seu filho se contrapõem às dúvidas, anseios e sentimento de abandono. Portanto, entendemos que a paternidade é um momento de construção, dinâmico e contínuo, galgado diariamente por meio das inter e intrarrelações do homem com sua família e dele com ele mesmo.

\section{MÉTODO}

Trata-se de uma investigação exploratória-descritiva, qualitativa, desenvolvida entre os meses de janeiro a abril de 2007. Participaram da pesquisa 15 homens. Como critério de inclusão, determinamos que os homens deveriam coabitar com suas esposas, estando essas no período puerperal. Este número foi determinado à medida que observamos a saturação das informações, ocorrida durante o processo de coleta de dados. Para esse fim, utilizamos um roteiro de entrevista semiestruturado constituído por duas partes: a primeira, subdividida em itens sociodemográficos e econômicos, com vistas a caracterizar os participantes, e a segunda parte, composta por questões específicas ao objeto de estudo.

Salientamos que o estudo foi submetido à apreciação pelo Comitê de Ética em Pesquisa da Universidade Federal do Rio Grande do Norte, obtendo aprovação sob o número 090/06.

Os dados foram coletados em domićlios localizados no Distrito Sanitário Oeste, no município de Natal/RN. Ressaltamos que antes de iniciarmos os questionamentos, explicamos ao pai a finalidade da pesquisa e as considerações contidas no Termo de Consentimento Livre e Esclarecido de acordo com a Resolução n ${ }^{196 / 96}$ do Conselho Nacional de Saúde. Estando o depoente de acordo com o que foi declarado, solicitamos que o mesmo assinasse o documento para só então seguirmos com as perguntas. Em concordância com o participante, utilizamos um gravador portátil para apreendermos melhor os depoimentos.

Os depoimentos relativos ao objeto de estudo foram tratados em conformidade com a técnica de análise de conteúdo, na modalidade de análise temática, discutidos com base no levantamento da literatura e analisados à luz dos princípios do interacionismo simbólico ${ }^{11,12}$.

Como forma de garantir o anonimato dos participantes, atribuímos nomes fictícios a cada um deles.

\section{RESULTADOS E DISCUSSÃO}

Tratando da caracterização, afirmamos que a maioria dos participantes desta pesquisa é jovem, secundarista, mantém o convivio estável com suas companheiras, ganha entre dois e três salários mínimos e tem um filho.

Após o tratamento das falas, surgiram as seguintes categorias: Cuidando da companheira e da criança e Provendo o sustento da família, as quais foram analisadas à luz dos 
princípios do interacionismo simbólico, segundo Blumer, a saber: o ser humano age com relação às coisas na base dos sentidos que elas têm para ele. Estas coisas incluem todos os objetos físicos, outros seres humanos, categorias de seres humanos (amigos ou inimigos), instituições, idéias valorizadas, atividades dos outros e outras situações que o indivíduo encontra na vida cotidiana; 2.0 sentido destas coisas é derivado ou surge da interação social que alguém estabelece com o outro; 3 . Esses sentidos são manipulados e modificados através de processos interpretativos usados pela pessoa ao tratar as coisas que ela encontra ${ }^{12}$.

\section{Cuidando da companheira e da criança}

Nesta categoria, podemos observar expressões de cuidado, emitidas pelos pais, em relação à companheira no puerpério:

É um momento que é pra tratar dela, cuidar dela, pra não acontecer nada com ela. (Berilo)

Mas aí eu fico dizendo pra ela ó, você tem que andar, caminhar foi a enfermeira que disse. Ela fica cuidando do menino e eu cuido dela. (Ortoclásio)

É uma época de cuidado, pra não quebrar, não acontecer alguma coisa com ela (esposa). (Peridoto)

Considerando as expressões de significado emitidas pelos depoentes, o pós-parto é uma fase em que a esposa precisa ser cuidada. Berilo menciona a palavra "cuidar" e apresenta a ideia de prevenção - pra não acontecer nada com ela - velada em suas palavras. Essa concepção é reforçada no discurso de Ortoclásio quando reconhece e recomenda que a parceira ande, caminhe durante o puerpério. Assim sendo, acreditamos que o companheiro percebe o puerpério como uma fase que requer cuidados. Ele preza pelo bem-estar da companheira, pois a orienta com conselhos que remetem ao cuidado em saúde inerentes ao puerpério, como, por exemplo, a deambulação.

A deambulação precoce após o parto favorece o restabelecimento físico da mulher, além de ajudá-la a retomar o autocuidado. Essa prática é encorajada pelo Ministério da Saúde desde o puerpério imediato, ainda em ambiente hospitalar ${ }^{13}$. Nesse sentido, os discursos dos participantes sugerem três interpretações: o companheiro recebeu orientação direta sobre os benefícios da deambulação precoce; adquiriu conhecimentos quanto a essa prática por meio de leituras; ou captou, indiretamente, as recomendações oferecidas pelo(a) enfermeiro(a) a sua companheira por ocasião da alta hospitalar.

Analisando o contexto da categoria em apreço, acreditamos que a terceira possibilidade é a mais provável de ter acontecido, pois poucos são os profissionais que incluem homens e mulheres como corresponsáveis pela saúde no período puerperal. Dessa forma, salientamos a importância das ações de enfermagem e da participação do pai nesse momento, visto que ele faz clara citação a esse profissional, demonstrando confiança em sua orientação.

Convém destacarmos a relação que o pai apresenta entre a mãe e o recém-nascido. Para Ortoclásio, o cuidado estende-se não somente à saúde da companheira, mas também à criança, pois se algo acontecer com ela, atingirá seu filho, já que esse depende totalmente da genitora, como podemos observar na seguinte expressão: - Ela fica cuidando do menino e eu cuido dela.

Cuidar é uma atitude que representa uma ação de envolvimento afetivo com o outro ${ }^{14}$. Nessa vertente, analisando a fala de Peridoto, deduzimos haver preocupação e afeto para com sua companheira já que revela atitudes de cuidado.

De um modo geral, alguns participantes conceberam que, durante o pós-parto, a companheira precisa ser ajudada, como também demonstraram atitudes de precaução e dedicação com a saúde do filho, observadas nas falas dos entrevistados:

Etem que ter atenção redobrada com a criança. (Prásio)

Agente procura, eu procuro junto com minha esposa saber como é que estão as vacinas dele (criança), [...] e já consegui encaminhar um plano de saúde pra ele (criança) [...]. (Quartzo)

Aatividade de cuidar dos filhos é representada no imaginário social como uma função natural da mulher, já que o trabalho na sociedade é organizado por gênero e não prevê a participação masculina nas tarefas familiares. No universo cultural construído acerca da maternidade, o cuidado se estabelece regido pelo gênero e intimamente associado às mulheres. Entretanto, em diversas áreas, os pais, além de serem reconhecidos como afetivamente importantes para os filhos, também são considerados aptos para providenciarem todos os cuidados necessários ao bem-estar destes, inclusive aqueles antigamente restritos às mães ${ }^{15}$.

A figura do pai contemporâneo é construída, sobretudo, levando-se em consideração a capacidade do homem de perceber e de reconhecer suas necessidades afetivas, estimulando o desabrochar do cuidado em família, ainda que encoberto por preconceitos machistas.

A prática do cuidado requer conhecimento do ser cuidado. 0 cuidador deve ser capaz de entender as necessidades do outro e responder a elas de forma adequada, em uma relação que fortaleça o "self" do outro. Nessa discussão, a interação entre os seres merece ser refletida no sentido de identificar as repercussões desse processo na vida do cuidador ${ }^{14}$.

Diante disso, com base nas premissas do interacionismo simbólico, podemos dizer que a ação do pai é determinada pelo resultado da interação dele consigo mesmo, com sua companheira, filho e ambiente no qual está inserido. Sua 
atitude de cuidar é construída em resposta ao significado que a esposa e o filho têm para ele como partes do seu núcleo familiar. Desse modo, o homem apresenta-se como partícipe de um contexto que também precisa de cuidados.

Destacamos ainda que alguns pais afirmaram não entender aspectos relacionados à reprodução e ao organismo feminino, enfatizando a necessidade de conhecimento, como podemos perceber na fala de Diamante. Esse entrevistado deixa subentendido que o cuidador precisa conhecer aspectos inerentes ao ser cuidado:

Eu queria saber mais, sabe? Pra entender. Eu acho que o homem deveria saber mais sobre as esposas. Esse negócio de menstruação, gravidez, sabe? Essas coisas de mulher. (Diamante)

Esta narrativa reafirma a acepção de que o homem é colocado à margem do processo reprodutivo, pois, nos dias atuais, encontramos poucas estratégias direcionadas a ele. Alguns pais, mesmo enfrentando grandes barreiras de conhecimentos, sociais e psicológicas, participam de momentos únicos junto a seus filhos, bem como à companheira, durante o ciclo gravídico-puerperal.

Sobre esse aspecto, durante a gestação, o pai refere participar da gravidez com sentimentos e atitudes voltados ao ato de cuidar traduzido como preocupação, ajuda, presença e responsabilidade 5 . Tratando-se do parto, os pais acompanhantes são carentes de informações. Eles não sabem como cooperar, agem por intuição e tendem a demonstrar medo, já que não recebem orientações acerca desses assuntos. Logo, tornam-se espectadores, e não acompanhantes do parto ${ }^{16}$.

Sob a ótica do interacionismo simbólico, somos levadas a considerar que o homem no puerpério, interagindo com ele próprio e com o ambiente que o cerca, cuida tanto da esposa como da criança nessa fase. Assim, o pós-parto adquire um sentido de cuidado.

Os entrevistados referiram ainda vivenciar o puerpério da parceira sem disponibilidade de tempo:

Então ela precisa de mais atenção da gente. Só cinco dias é pouco tempo pra dar assistência a ela. Acho que [...] dez dias [...] seria ideal. (Diopsídio)

\section{A licença-paternidade não dá pra fazer nada. Eu ganhei mais uns dias de folga que eu conseguipor fora, aí completou os dez dias. Assim, dá pra fazer alguma coisa pra criança. Eu fico com dedicação exclusiva para ela, sem me preocupar com o trabalho. Aífica bom esses dez dias. (Prásio)}

Esses depoimentos revelam que o homem tende a dedicase mais às atividades no lar após o nascimento do filho, objetivando suprir as necessidades que o novo integrante proporciona. Todavia, esse pai acaba permanecendo pouco tempo na família e considera que a licença oferecida a ele, por direito, não atende as precisões básicas e compromissos impostos pela condição da paternidade. Segundo as falas de Diopsídio e Prásio, o período da licença-paternidade é insuficiente, visto que a família requer mais atenção e cuidados durante o pós-parto.

O período de tempo destinado à licença-paternidade não supre as necessidades imediatas do casal após o nascimento do filho. A permissão em pauta deveria levar em consideração não só os aspectos burocráticos - como o registro civil da criança-, e sim as novas emoções que brotam desse momento. Reconhecemos ainda que as novas precisões surgidas no homem, durante o período do pós-parto da companheira, vão além dos sentimentos citados. Somam-se a estes o desejo referido pelos entrevistados em desenvolver ações de cuidados relativos à mulher, à criança e ao lar.

No que diz respeito à paternidade, a ausência masculina, no âmbito da sexualidade e da reprodução, tem raízes profundas. Reflete valores norteados por um tipo ideal de masculinidade baseado na assimetria das relações de gênero, como também em uma visão de mundo em que homens e mulheres desempenham papéis diversos, particularmente no campo da reprodução, do cuidado das crianças e da casa. $\mathrm{Na}$ década de 1980, o Conselho Nacional dos Direitos da Mulher, em articulação com outros Conselhos e movimentos sociais, apresentou uma proposta no sentido de incluir, na nova Constituição, a licença-paternidade com o objetivo de trazer o homem para dentro de casa com o nascimento do filh ${ }^{17}$.

A Constituição de 1988 criou a licença-paternidade de curta duração, que quando regulamentada, tem um efeito simbólico, pois não excede uma semana. Entretanto, ainda é predominante, nas relações de gênero, uma perspectiva demarcada pelo modelo tradicional de divisão sexual de tarefas que justifica e legitima, para homens e mulheres, a ausência masculina no espaço doméstico, mesmo quando ambos dedicam tempo similar ao trabalho fora de casa ${ }^{17}$.

Com base no primeiro princípio do interacionismo simbólico, nos é possível afirmar que, embora o papel do homem na sociedade se encontre em processo de transição, os entrevistados, durante o puerpério, revelaram interagir consigo mesmo sob as concepções de gênero. Dessa forma, constroemse como seres responsáveis na perspectiva de garantirem o sustento da companheira e filho, embora deem uma resposta negativa ao tempo destinado à licença-paternidade quando associada à prestação de cuidados. Na opinião de Diopsídio, 0 tempo é limitado e restringe atitudes de cuidado deste com sua família, o que é expresso na fala:

Então ela precisa de mais atenção da gente. Só cinco dias é pouco tempo pra dar assistência a ela. (Diopsídio) 
Considerando a categoria em apreço cuidando da companheira e da criança, as reflexões nos levam a afirmar que o homem se encontra favorável ao puerpério, porém, em seu cotidiano, depara-se com aspectos que representam obstáculos a sua participação nos cuidados com a mulher e filho, tais como falta de conhecimento acerca do processo reprodutivo e indisponibilidade de tempo.

\section{Provendo o sustento da família}

As narrativas revelam que os homens assumem, durante 0 pós-parto, o papel de provedor da família na perspectiva de garantir o sustento da mulher e dos filhos. Tal entendimento fica explícito nas falas de Coríndon e Esfênio quando afirmam que trabalham muito para manter o lar, colocar comida em casa e sustentar a filha, como mostram as falas:

Eu trabalho, trabalho muito, sabe? Pra manter em casa. (Coríndon)

Aí eu trabalho mesmo, pra botar comida em casa [...] pra poder sustentar minha filha. Faço frete. A gente tem que se virar no que pode, né? (Esfênio)

Identificamos ainda que a preocupação com o sustento financeiro da família inicia-se desde a gestação, como revelado no seguinte depoimento:

\section{[...] não posso dizer que tenho muita dificuldade por que antes de ele nascer eu já vinha me prevenindo (poupança, dinheiro). (Diamante)}

Determinados aspectos merecem destaque, como, por exemplo, as expressões de intensidade - eu trabalho muito e eu trabalho mesmo- observadas nos discursos. Coríndon e Esfênio utilizam as palavras muito e mesmo, ampliando, assim o sentido de prover financeiramente a família; isto reforça a concepção da divisão sexual do trabalho, em que cabe ao homem a responsabilidade de buscar, cada vez mais, recursos, com vistas a suprir as necessidades familiares. Nesse sentido, no entendimento dos depoentes, a paternidade pode significar aumento da responsabilidade financeira traduzida pela preocupação em fornecer a sua família uma melhor qualidade de vida, como revelam os depoimentos:

Antes eu vivia sem fazer nada, agora eu tenho meu filho e tenho que criar ele. Émais responsabilidade, eu acho. Com a minha família. (Berilo)

Agora com mais responsabilidade pra criar $e$ sustentar [...] aíaumentou as dívidas. Com criança em casajá viu, né? (Crisoberilo)
Aí depois que eu tive meu filho [...] aluguei uma casa pragente morar e a responsabilidade mudou. Eu tenho uma responsabilidade maior. (Diamante)

Tô trabalhando agora mais. Antes eu trabalhava meio, assim, meio preguiçoso, porque não tinha a responsabilidade, né? Mas agora eu tenho mais responsabilidade, comeceia dar valor pro meu trabalho pra receber meu salário e ajudar minha família. (Topázio)

O termo responsabilidade aparece de forma unânime. Os pais expressam ter mais compromisso com sua família após o nascimento do filho. Essa atitude, na maioria das vezes, está associada ao sustento financeiro, como também à presença do recém-nascido. Isso nos leva a deduzir que a chegada do filho faz surgir ou aumentar essa ação.

Nesse sentido, estudos demonstram que, durante a gestação, o aumento da responsabilidade fez-se presente nos relatos dos entrevistados. Esse encargo estava associado à manutenção do emprego, ao provimento de bens materiais e à estabilidade no relacionamento do casal $^{5}$.

Refletindo sobre os depoimentos acima citados, podemos constatar uma forte herança do patriarcado, em que cabe ao bom pai prover o sustento financeiro familiar. Convém ressaltar que, nos dias atuais, muitos núcleos humanos ainda sofrem influência da sociedade patriarcal, embora os papéis designados aos homens e às mulheres estejam mudando de maneira considerável.

No estudo em apreço, podemos observar que o pai provedor, destacado nos discursos dos entrevistados, vem acompanhado de ações de cuidado e envolvimento com a esposa e filho. Diante disso, somos levadas a acreditar que os companheiros vêm se distanciando da condição unicamente financeira, tendendo a caminhar para uma redefinição de papéis, tornando-se copartícipes no cuidado e na vida familiar. Tal concepção nos remete ao cuidado humano, já que este representa uma maneira de ser e de se relacionar, caracterizado por envolvimento, interesse e compromisso moral, manifestações estas que são exclusivas dos seres humanos. ${ }^{14}$

Tratando-se dos entrevistados, esses homens, no seu processo de interação simbólica, ainda associam a figura paterna ao provimento financeiro, pois revivem esse momento permeado por concepções de gênero arraigadas à ideologias que perduram até os dias atuais. Esta representação não é mais unânime, pois vem cedendo lugar para atitudes de cuidado e envolvimento familiar.

Portanto, esses homens relacionam o puerpério ao cuidado, desenvolvendo uma atitude positiva no que se 
refere ao cuidar da mulher e da criança e ao sustento da família, embora, no seu cotidiano, deparam-se com a mediação da esposa, sogra e/ou demais integrantes do núcleo familiar.

\section{CONCLUSÕES}

Nos últimos anos, aspectos relativos ao comportamento do homem no cenário da reprodução humana vêm despertando interesse de estudiosos. Ao investigarmos as ações desenvolvidas pelo homem durante o puerpério, consideramos que ele interage consigo mesmo, com a parceira, filho e ambiente familiar. Nesse processo, sua experiência ocorre sob os conceitos que envolvem a atitude de cuidar. Além disso, o conteúdo das falas revelou a forte presença do pai provedor. Esse fato, sob as concepções de gênero, remete-nos à paternidade tradicional, uma vez que esta se apresenta arraigada à cultura masculina. Contudo, entendemos que o homem caminha em direção à mudança de papel, à medida que se coloca à disposição para cooperar nos cuidados e tarefas domésticas, reconhecendo que sua família necessita de maior atenção durante o pós-parto.

Após mergulhamos nas falas dos entrevistados, trouxemos as três premissas do interacionismo simbólico, segundo

\section{REFERÊNCIAS}

1.Marcolino C, Galastro EP. As visões feminina e masculina acerca da participação de mulheres e homens no planejamento familiar. Rev Latino-am Enfermagem 2001 maio; 9(3): 77-82.

2.Maldonado MT, Dickstein J, Nahoum JC. Nós estamos grávidos. São Paulo(SP): Saraiva; 2000.

3.Schraiber LB, Gomes R, Couto MT. Homens e saúde na pauta da saúde coletiva. Cienc Saude Colet 2005 jan/mar; 10(1): 7-17.

4.Falceto OG. A influência de fatores psicossociais na interrupção precoce do aleitamento materno. [tese de doutorado]. Porto Alegre (RS): Pós-Graduação em Medicina, Clínica Médica/ UFRS; 2002.

5.Brito RS, Almeida MS. Ciclo gravídico puerperal: participação do marido/ companheiro. Relatório Técnico-científico 1999. Natal (RN); 1999.

6.Silveira IP, Campos ACS, Mello MS, Fernandes AFC. A percepção do pai frente ao nascimento do seu filho. Rev RENE 2000 jul/dez; 5(2): 23-27.

7.Lowdermilk DL, Perry SS, Bobak IM. 0 cuidado em enfermagem materna. Porto Alegre (RS): Artmed; 2002.

8.Abuchaim I. Emoções na gravidez, no parto e no puerpério. Rev AMRIGS 1979 out/dez; 23(4): 07-09.

9.Brito RS, Oliveira EMF. Aleitamento materno: mudanças ocorridas na vida conjugal do pai. Rev Gaucha Enferm 2006 jun; 27(2): 193202.
Blumer $^{12}$, como suporte para a análise. Assim, respondendo ao objetivo proposto no estudo, afirmamos que os depoentes: interagem e participam do puerpério, desenvolvendo atitudes de cuidado com a companheira, oferecendo conselhos que remetem ao restabelecimento físico e a prevenção de agravos, como o estímulo à deambulação; desenvolvem atitudes de dedicação e preocupação com a saúde do filho; consideram que a licença-paternidade não atende às suas necessidades de tempo junto à esposa e ao filho; reconhecem que a companheira e o recém-nascido requerem mais dedicação-tempo após o parto; desempenham papel de provedor no intuito de garantir o sustento familiar; preparam-se financeiramente para a chegada do filho; e referem que sua responsabilidade aumenta após o nascimento da criança.

Por fim, salientamos que alguns aspectos em relação à interação pai-filho durante os primeiros dias após o parto da companheira precisam ser investigados e aprofundados, objetivando favorecer o vínculo afetivo, bem como a sua vivência durante a fase que procede ao nascimento. Faz-se necessário incentivar, dentro de uma visão holística do conhecimento, a discussão de aspectos que envolvem o homem adulto entre os estudantes da área da saúde, em especial de enfermagem, por lidar com o ser humano de forma integral no contexto familiar.

10. Afonso E. 0 pós-parto: dificuldades vividas pela mulher e apoio encontrado. [on-line] [dissertação de mestrado] 2002; [citado 7 nov 2004] [aprox 16 telas]. Disponível em : uww.portalbvsenf.eerp.usp.br/scielo

11.Bardin L. Análise de conteúdo. Lisboa (PT): Ed 70; 2000.

12.Blumer H. Symbolic interactionism: perspective and method. Califórnia(USA): Prentice-Hall; 1969.

13.Ministério da Saúde (BR). Parto, aborto e puerpério: assistência humanizada à mulher. Brasília (DF); 2001.

14.Waldow VR. 0 cuidado na saúde: as relações entre o eu, o outro e o cosmos. Petrópolis (RJ): Vozes; 2004.

15. Stefanello J. A vivência do cuidado no puerpério: as mulheres construindo-se como mães [dissertação de mestrado]. Ribeirão Preto (SP): Escola de Enfermagem / USP; 2005.

16. Carvalho MLM. Participação dos pais no nascimento em maternidade pública: dificuldades institucionais e motivações dos casais. Cad Saude Publica 2003; 19(2): 389-98.

17. Banco Mundial. A questão de gênero no Brasil. Brasília (DF); 2003.

18. Penna LHG, Carinhanha JI, Rodrigues RF. A mulher no pósparto domiciliar: uma investigação sobre essa vivência. Esc Anna Nery Rev Enferm 2006 dez; 10(3): 448-55. 